\title{
USING GUYANA'S MONITORING REPORTING \& VERIFICATION SYSTEM TO GUIDE NATIONAL FOREST MANAGEMENT \& DECISION MAKING
}

\author{
Nasheta Dewnath ${ }^{1}$, Pradeepa Bholanath ${ }^{1}$, Rosa Rivas Palma ${ }^{2}$, Blair Freeman ${ }^{2}$, Pete Watt ${ }^{2}$ \\ ${ }^{1}$ Guyana Forestry Commission, 1 Water Street, Georgetown, Guyana - ndewnath@gmail.com, \\ project.coordinator@forestry.gov.gy \\ ${ }^{2}$ Indufor Asia Pacific Ltd, Auckland City 1147, New Zealand - \\ rosa.rivaspalma@indufor-ap.com, blair.freeman@indufor-ap.com, pete.watt@indufor-ap.com
}

KEY WORDS: Guyana, REDD+, Satellite Data, Forest Management, Decision Making

\begin{abstract}
:
The Guyana Forestry Commission's (GFC) Monitoring, Reporting and Verification System (MRVS) is a combined Geographic Information System (GIS) and field-based monitoring system, which has underpinned the conducting of a historical assessment of forest cover as well as eight national assessments of forest area change to date. The System seeks to provide the basis for measuring verifiable changes in Guyana's forest cover and resultant carbon emissions from Guyana's forests, which will provide the basis for results-based REDD+ compensation in the long-term. With the continuous compilation, analysis and dissemination of MRVS results on a typically annual basis, the GFC envisioned a larger role for this data, in informing national processes such as natural resources policy and management. This resulted in a significant broadening of the application of the MRVS data and products for purposes that are aligned or complementary to national REDD+ objectives and forest policy and management. These broader applications have allowed for a beneficial shift towards the increased use of remote sensing data and scientific reporting to inform forest management, governance and decision making on natural resource management across forested land. This has resulted in a transformation in the nature of data available to inform decision making on forest management and governance, and overall environmental oversight, from predominantly social science data and factors to now incorporating remote sensing and scientific observations and reporting. Primary decision makers are turning to scientific based reporting to determine best approaches for developmental initiatives in Guyana. This study shows how Guyana has demonstrated significant progress in making remote sensing products accessible and useful to policy makers in Guyana.
\end{abstract}

\section{INTRODUCTION}

Guyana's forests cover approximately $87.5 \%$ of the country and contain an estimated 19.5 billion tons (or Gt) of $\mathrm{CO}_{2}$ in live and dead biomass pools (GoG, December $2014)^{1}$. Recognising the value of this extensive natural capital, the Government of Guyana (GoG) has engaged in a national programme to protect and maintain its forests, to reduce global carbon emissions and promote development along a green development pathway.

Guiding the continued protection and conservation of Guyana's forests is the Green State Development Strategy (GSDS), which is built on a vision of "green, inclusive development based on sound education and social protection, low-carbon resilient development, green and decent jobs, economic opportunities, individual equality, justice, and political empowerment" (GoG and UNEP, 2017). Key areas of focus within the GSDS are improvements in land use planning, sustainable agriculture, sustainable forest management (encompassing timber harvesting and non-timber forest products), freshwater management and the conservation of coastal ecosystem services.

In this context, this paper describes the use of Guyana's national forest cover monitoring program to inform decision-making on forest management and natural resource management across a broad range of sectors.

\subsection{Guyana-Norway Agreement}

In November 2009, the Government of Guyana and the Kingdom of Norway entered into a bilateral agreement regarding cooperation on issues related to mitigating climate change. More specifically, it addressed reducing emissions from deforestation and forest degradation (REDD+) in developing countries, biodiversity protection and the enhancement of sustainable, low carbon development (Joint Concept Note, 2012).

While committing up to US\$250 million over the five years of the Agreement, Norway's level of support was to be determined by Guyana's performance, measured against two sets of indicators:

- Indicators of enabling activities: These were a set of policies and safeguards designed to ensure REDD+ efforts contribute to the achievement of the goals set out in the Agreement. These indicators spoke to arrangements to ensure systematic and transparent multi-stakeholder consultations throughout the process; protection of the rights of Indigenous peoples; ensuring environmental integrity and biodiversity protection; ensuring continuous improvements in forest governance; and providing transparent,

\footnotetext{
${ }^{1}$ The Reference Level for Guyana's REDD+ Program, December 2014
} 
accountable oversight and governance of the financial support received.

- REDD-plus Performance Indicators: A set of forest-based greenhouse gas emissions-related indicators. It was agreed these indicators would gradually be replaced as the monitoring, reporting and verification system became fully operational. The indicators were developed based on conservative estimates while encouraging the development of a more accurate system over time through building national capacities.

Under the Guyana-Norway Agreement, Guyana developed its Monitoring, Reporting and Verification System (hereafter, MRVS) for REDD+. The MRVS is a combined GIS-based and field-based monitoring system developed to track national-level forest change of deforestation and forest degradation. It was developed to be the primary mechanism to measure Guyana's performance against the agreed indicators as set out in the agreement. Furthermore, it was required for the acquisition and analysis of ground-based and satellite data to report on forest cover and change on a predominantly annual basis.

The MRVS allowed for Guyana to conduct a historical assessment of forest cover (with 2009 as the baseline year), and eight national assessments of forest area change to date. National assessments for Years 1-7 (2009-2017) have been completed and the results disseminated to stakeholders; the national assessment for Year 8 (2018) is currently being completed.

The Guyana Forestry Commission (GFC) has led the development and implementation of the MRVS. Its development was guided by extensive engagement and consultation with government agencies, international experts and non-government stakeholders in Phase 1 (2010-2014); and this broad-based engagement continues through Phase 2 (2015- 2020²).

Over the years, significant progress has been made in the development of the MRVS; not only in the building of local capacities to manage and operate the System, but in technologies and techniques used to monitor forest change. The data collected over the period 2009 to 2018 has been stored in a repository that has been used primarily to facilitate reporting to Norway to trigger payments under the agreement.

As the MRVS continues to evolve, so has the vision for the role of the System in Guyana. The GFC sees a broadening of the current role of the System, from annual performance reporting to supporting forest and environmental management, governance and decision making within the natural resources sectors. The MRVS can be used further to report on Guyana's progress in the implementation of international commitments to the United Nations Framework Convention on Climate Change (UNFCCC) as well as supporting the country's implementation of the indicators of the Sustainable Development Goals.
This Paper describes the development of the MRVS, its applications and the approaches made to move the System towards this vision.

\subsection{MRVS Phase 1 - Development of the System}

The primary focus of Phase 1 of the MRVS was the development of the System. A Roadmap was developed to guide the development of the MRVS over the period 2009 to post 2012. The aim of the Roadmap in Phase 1 was to establish a comprehensive national system for monitoring, reporting and verifying forest carbon emissions resulting from deforestation and forest degradation in the country.

The Terms of Reference for Developing Capacities for a national Monitoring, Reporting and Verification System to support REDD+ participation of Guyana Background, Capacity Assessment and Roadmap (2009) ${ }^{3}$ set out the key building blocks for the development of the MRVS. This sought first to identify the requirements for the System, which are based on the internationally accepted principles and guidance at the international level, as specified by the IPCC Good Practice Guidelines and Guidance for reporting.

The Phase 1 Roadmap further sought to develop the local capacities to implement MRV through the development of a detailed plan to establish and sustain MRV capacities within the country. A detailed capacity assessment was conducted on the state of local capacities in keeping with the requirements for a MRVS; and this informed the development of a capacity building roadmap ${ }^{4}$.

Over the period 2009 and 2014, the GFC was able to take progressive steps to build a full MRVS in three different phases: (i) National Strategy Formulation, (ii) Country Readiness Phase and (iii) Implementation. The result was a sustainable, efficient national mechanism and an accompanying institutional framework with competencies for MRVS at different levels. Through the implementation of Phase 1, significant achievements were made in conducting a national forest monitoring program and MRVS. The System has served to report on the country's performance against the "REDD+ Interim Indicators" agreed upon between the Governments of Guyana and Norway.

It also enabled Guyana to make significant contributions to the global dialogues on REDD+. In the context of evolving guidance from the UNFCCC forums regarding MRVS and methodologies, Guyana has been able to demonstrate significant progress in the piloting of methodologies and data collection techniques. Guyana has been able to share lessons and take stock of those lessons for the future as well as working closely with the international community and high-level stakeholders.

\subsection{MRVS Phase 2 - Consolidating and expanding capacities for national REDD+ monitoring}

The activities planned for implementation during the Phase 2 of the MRVS $(2015$ - 2019) were designed to support the establishment and maintenance of a worldclass MRVS as a key component of Guyana's national

Guyana Background, Capacity Assessment and Roadmap, November 13, 2009

${ }^{4}$ Ibid. 
REDD+ programme. This System will provide the basis for measuring verifiable changes in Guyana's forest cover and the resultant carbon emissions as an underpinning for results-based REDD+ compensation in the long-term.

The objective of the Phase 2 Roadmap 5 is to consolidate and expand capacities for national REDD+ monitoring and MRVS. It has sought to support Guyana in meeting the evolving reporting requirements from the UNFCCC while continuing to fulfil additional international reporting requirements, as well as support Guyana in further developing forest monitoring as a tool for REDD+ implementation. The Phase 2 Roadmap sought to enable Guyana to fulfil its REDD+ objectives to:

- Underpin and stimulate strategies and priorities for REDD+ implementation

- Track performance of REDD+ activities and their impacts (carbon \& non-carbon)

- Continue to support the building of capacity for MRV implementation at the government and nongovernment level and other parties that have a role in MRVS related activities.

Three key activities recommended for Phase 2 in order to consolidate and expand capacities included:

a) Consolidate capacities and routine REDD+ monitoring and MRV

b) Develop national forest monitoring as a tool for REDD+ implementation

c) Facilitate knowledge sharing and capacity building

\section{MRVS DATA}

Over the duration of the Guyana-Norway Agreement (2009- 2014), the focus of the MRVS (Phase 1) was the production of annual performance reports against this framework of Interim Indicators. These performance reports (the MRVS Interim Measures Reports) detailed forest change by activity data and related emissions. Phase 1 of the MRVS produced the following reports (Table 1):

\begin{tabular}{|c|c|}
\hline Report & Time period included \\
\hline Historic assessment & 1990 to Sept 2009 \\
\hline $\begin{array}{l}\text { Year 1: First annual } \\
\text { assessment }\end{array}$ & $\begin{array}{lcc}1^{\text {st }} \quad \text { October } 2009 & \text { to } \\
30^{\text {th }} & \text { September } 2010\end{array}$ \\
\hline $\begin{array}{l}\text { Year 2: Second annual } \\
\text { assessment }\end{array}$ & $\begin{array}{l}1^{\text {st }} \text { October } 2010 \text { to } \\
31^{\text {st }} \text { December } 2011\end{array}$ \\
\hline $\begin{array}{l}\text { Year 3: Third annual } \\
\text { assessment }\end{array}$ & $\begin{array}{l}1^{\text {st }} \text { January } 2012 \text { to } \\
31^{\text {st }} \text { December } 2012\end{array}$ \\
\hline $\begin{array}{l}\text { Year 4: Fourth annual } \\
\text { assessment }\end{array}$ & $\begin{array}{l}1^{\text {st }} \text { January } 2013 \\
31^{\text {st }} \text { December } 2013\end{array}$ \\
\hline $\begin{array}{l}\text { Year 5: Fifth annual } \\
\text { assessment }\end{array}$ & $\begin{array}{l}1^{\text {st }} \text { January } 2014 \\
31^{\text {st }} \text { December } 2014\end{array}$ \\
\hline
\end{tabular}

Table 1 -List of reports completed under Guyana Norway Agreement/MRVS Phase 1 (2009 to 2014)

Guyana was able to secure continued support from the Government of Norway for implementation of Years 6-9 (2015- 2019) of the MRVS under Phase 2. This will lead 5 Terms of Reference for continuing to Develop Capacities for a National
Forest Monitoring and Measurement, Reporting and Verification System to Support REDD+ Participation of Guyana, Roadmap Phase 1 to an additional set of MRVS Interim Measures Reports (Table 2):

\begin{tabular}{|c|c|}
\hline Report & Time period included \\
\hline $\begin{array}{l}\text { Year 6: Sixth annual } \\
\text { assessment }\end{array}$ & $\begin{array}{lrr}1^{\text {st }} \quad \text { January } & 2015 \text { to } \\
31^{\text {st }} \text { December } & 2016 \\
(24 \text { months }) & \end{array}$ \\
\hline $\begin{array}{l}\text { Year 7: Seventh annual } \\
\text { assessment }\end{array}$ & $\begin{array}{lcc}1^{\text {st }} & \text { January } & 2017 \\
31^{\text {st }} & \text { December } & 2017\end{array}$ \\
\hline $\begin{array}{l}\text { Year 8: Eight annual } \\
\text { assessment }\end{array}$ & $\begin{array}{lcc}1^{\text {st }} & \text { January } & 2018 \\
31^{\text {st }} & \text { December } 2018\end{array}$ \\
\hline $\begin{array}{l}\text { Year 9: Ninth annual } \\
\text { assessment }\end{array}$ & $\begin{array}{lcc}1^{\text {st }} & \text { January } & 2019 \\
31^{\text {st }} & \text { December } & 2019\end{array}$ \\
\hline
\end{tabular}

Table 2 -List of reporting under MRVS Phase 2 (20152019)

\subsection{Satellite Imagery}

Reporting under the MRVS draws on a combination of ground-based and satellite data. As the MRVS has evolved, so has the data that has been used; most notably, the satellite data.

In 2009, as work commenced on the analysis of historical change in forest cover, freely available Landsat imagery at 30 metre resolution was acquired and used. This covered the period 1990-2009. The reporting for Year 1 (2010) utilised a combination of DMC (32 m) and Landsat imagery.

From 2011 to 2014, the data utilised was purchased from RapidEye at 5 metre resolution.

Forest change mapping conducted for 2015 and 2016 (Year 6) acquired a combination of Landsat and Sentinel (10 metre resolution) data. The Sentinel (2A/2B) has been the primary dataset used for mapping of forest change since 2017, supplemented by Landsat.

The use of all of the above-mentioned satellite imagery providers (i.e. Landsat, DMC, RapidEye, Sentinel) has enabled Guyana to track land cover change greater than one hectare in size, and attribute this change to direct drivers (i.e. mining, shifting agriculture etc.).

Another aspect of the MRVS is conducting an Accuracy Assessment. The Accuracy Assessment is used to provide an evaluation of the quality of the GFC's mapping of change across Guyana's forests. Two datasets have been used to inform the Accuracy Assessment:

- High-resolution aerial photographs have been captured using a Cessna-mounted aerial multispectral imaging system. Image resolution ranges from about 25 to $60 \mathrm{~cm}$ (variations due to the altitude of the aircraft at the time of capture); and

- PlanetScope images as provided by Planet Labs. The Planet constellation comprises approximately 200 micro-satellites imaging areas at (approximately) 3-5 metre resolution.

Achievements, Evolving Requirements and Roadmap for Phase 2 Activities, September 19, 2014. 


\subsection{National Datasets}

Along with satellite data, a range of national datasets are incorporated in the MRVS for mapping of forest change. These datasets relate to infrastructure, mining concessions, agricultural leases, land tenure, protected areas etc. These datasets are managed across Government agencies involved in the active management and allocation of land resources in Guyana. The main Government agencies responsible for these functions and an overview of their relevant management datasets are set out in Table 3.

\begin{tabular}{|l|l|l|}
\hline Agency & Role & Datasets \\
\hline $\begin{array}{l}\text { Guyana Forestry } \\
\text { Commission } \\
\text { (GFC) }\end{array}$ & $\begin{array}{l}\text { Management of } \\
\text { forest resources }\end{array}$ & $\begin{array}{l}\text { Resource } \\
\text { management } \\
\text { related datasets }\end{array}$ \\
\hline $\begin{array}{l}\text { Guyana Geology } \\
\text { and Mines } \\
\text { Commission } \\
\text { (GGMC) }\end{array}$ & $\begin{array}{l}\text { Management of } \\
\text { mining and } \\
\text { mineral } \\
\text { resources }\end{array}$ & $\begin{array}{l}\text { Mining } \\
\text { concessions, } \\
\text { active mining } \\
\text { areas }\end{array}$ \\
\hline $\begin{array}{l}\text { Protected Areas } \\
\text { Commission } \\
\text { (PAC) }\end{array}$ & $\begin{array}{l}\text { Management of } \\
\text { Protected Areas } \\
\text { System in } \\
\text { Guyana }\end{array}$ & $\begin{array}{l}\text { Spatial } \\
\text { representations } \\
\text { of all protected } \\
\text { areas }\end{array}$ \\
\hline $\begin{array}{l}\text { Guyana Lands } \\
\text { and Surveys } \\
\text { Commission } \\
\text { (GLSC) }\end{array}$ & $\begin{array}{l}\text { Management of } \\
\text { land titling and } \\
\text { surveying of } \\
\text { land }\end{array}$ & $\begin{array}{l}\text { Land tenure, } \\
\text { settlement } \\
\text { extents and } \\
\text { country } \\
\text { boundary }\end{array}$ \\
\hline
\end{tabular}

Source: Guyana Forestry Commission (2018). Guyana REDD+ Monitoring Reporting \& Verification System (MRVS) Year 7 Interim Measures Report, November 2018.

Table 3- Primary agency datasets incorporated in MRVS

\section{EXISTING APPLICATIONS OF MRVS DATA}

As implementation of the second phase of the MRVS progressed, the data was used to inform several new applications for natural resource management by agencies that worked closely with the GFC. These applications included the identification of high intensity land uses related to forestry and mining activities, national protected areas planning, assessing land degradation, as well as subnational level MRV (Community MRV) activities. These activities are detailed below.

\subsection{Identification of areas of high intensity land use}

The Ministry of Natural Resources (MNR), which has oversight of the forestry and mining sectors in Guyana, has utilised the MRVS data to identify areas of relatively high-level activity (termed 'hotspots') to support the prioritisation of monitoring and compliance measures by these agencies. The MNR, as part of its oversight and governance functions, engages with GFC and the Guyana Geology and Mines Commission (GGMC) on the monitoring and compliance measures for these areas.

Though the MRVS data was used to inform this strategic analysis, the routine use of the MRVS data has not yet been mainstreamed within the MNR's management systems. A constraint they have identified in the use of the MRVS data has been the data lag associated with annual reports, in that the reporting conducted by the GFC is retrospective, rather than a near real time monitoring system.

\subsection{Analysis of Protected Areas for Nationally Determined Contribution commitments}

The MRVS data has been used as part of the national process for identifying additional areas to extend and expand the Protected Areas System in Guyana. In 2015, the President of Guyana announced the country's submission of its Nationally Determined Contribution (NDC) as part of landmark Paris Climate Change Agreement; and subsequently, the President confirmed that this contribution would include the conservation of an additional 2 million hectares through Guyana's National Protected Area System (NPAS) and other effective areabased conservation measures.

To implement this, the GoG and its implementing agencies worked together with non-government organisations (NGOs) including Conservation International (CI) to firstly identify candidate areas and then evaluate the respective benefits and costs ('tradeoffs') for each of these areas. Benefits and costs were addressed through a multi-criteria analysis, encompassing environmental, economic and social impacts for each of the sites. In addition, the analysis incorporated the objective of ensuring a geographic distribution across all the regions.

The lead agencies in the process, the Protected Areas Commission (PAC) and CI observed that MRVS data was one of the important spatial datasets used to identify forest cover and areas of forest cover change over time, as part of this comprehensive analysis of candidate areas across Guyana. Key considerations included deforestation rates within or around candidate areas, and 'hotspots' of relatively high intensity use in these areas.

While this comprehensive analysis is largely completed, the President has identified that the PAC is responsible for modifying (enlarging, extending and expanding) the NPAS to ensure that these targets are met. Under this mandate, there is scope for further analysis and ongoing monitoring of the NPAS over time, using MRVS data and other spatial datasets to monitor changes in land use, notably in forested areas.

\subsection{Assessment of land degradation on non-forest} land areas

The Guyana Lands \& Surveys Commission (GLSC) is actively engaged in the development of the MRVS, through regular inter-agency liaison and coordination with the GFC. Through these linkages, GLSC is highly familiar with the MRVS outputs and has sought to use these outputs for a broader range of purposes aligned with its mandate. GLSC acts as the custodian for all public lands, rivers and streams of Guyana and is the National Focal Point Agency of the United Nations Framework Convention to Combat Desertification (UNCCD).

With the acquisition of RapidEye 5 metre resolution data (2012-2014), the GFC has purchased user licences for the MNR, GLSC, the GGMC and the Environmental Protection Agency (EPA). The GLSC has access to the licence of the RapidEye imagery acquired for the MRVS assessment and has received the MRVS outputs based on this imagery. In the implementation of Guyana's Mainstreaming Sustainable Land Development and 
Management Project (Government of Guyana and FAO, 2017), the GLSC has used the RapidEye imagery to assess land degradation in the non-forest areas defined by the MRVS assessment. However, the GL\&SC has pointed out that the imagery has proven less suitable for:

- updating topographic maps that have a scale of 1:50,000 (some map scales are presented in metres, while some are presented in feet);

- geo-referencing of cadastral plans and detailed maps for land use planning.

A further limitation that the GLSC identified with the use of MRVS outputs to date is the resolution of the satellite imagery data available. The GLSC indicated that 2 metre resolution and lower would be required for the fulfilling of the GLSC's mandate.

\subsection{Capacity Building for Community MRV}

Community Monitoring, Reporting and Verification (CMRV) involves the training of local people in the Monitoring, Reporting and Verification (MRV) process, for measurement and monitoring of the impacts of the drivers of forest change at the community level. It has the potential to add immensely to the REDD+ movement in Guyana, especially the national MRV system. The GFC continues to build the capacities of local communities to undertake CMRV as part of the process of participating in REDD+. The GFC is seeking to create synergies between CMRV and the national MRVS whereby communities will be part of the reporting framework so as to inform annual national reporting; and will also be able to verify what is reported by the GFC.

For this process to realize its full potential, local capacities would need to be built within the communities that are interested in participating in a REDD+ scheme. This would include the theoretical and practical aspects of REDD+, MRV and CMRV, as well as training in the use of field equipment and devices and the management of financial and human resources.

The data generated from CMRV can be used to prepare baseline information on forest resources available and changes, which can assist local communities and government institutions in the management of their natural resources, adapting land use practices and other socio-economic issues.

\subsection{Other interagency applications}

The use of the MRVS in the areas outlined above led the GFC to conduct a national review aimed at identifying all the current applications of the MRVS data and outputs; and then identifying potential options for further use for purposes that are broadly aligned or otherwise complementary with national REDD+ objectives and forest resources policy and management in Guyana. The national review sought to:

a) ascertain how MRVS outputs are supporting existing land use policies and regulations, including land use allocation processes in Guyana;

b) establish how well the range of existing national policies and regulations are aligned in relation to the application of MRVS outputs across sectors;

c) identify the potential for broader application of the MRVS for the benefit of other sectors and the management of Guyana's natural resources; and d) provide findings and recommendations from the review, with a principal focus on opportunities for strengthening the monitoring functions of the MRVS, and the planning and enforcement functions for Government agencies.

In this review, conducted in 2018, a broad range of national stakeholders were consulted, many of whom indicated keen interest in gaining access to the current MRVS data. As a result, the GFC was able to build on or in some cases establish relationships with agencies and academia, involved in environmental management, mangrove protection, national infrastructural development and disaster management among others. The applications for MRVS data applied to date are outlined in the summary below (Table 5).

\begin{tabular}{|l|l|}
\hline Application & Impacts and beneficiaries \\
\hline $\begin{array}{l}\text { Planning for, } \\
\text { mapping and } \\
\text { monitoring of forest } \\
\text { cover change within } \\
\text { Protected Areas }\end{array}$ & $\begin{array}{l}\text { Impacts: Enhanced } \\
\text { capabilities within the PAC } \\
\text { for planning, monitoring } \\
\text { and measuring forest } \\
\text { change by driver within } \\
\text { Protected Areas } \\
\text { Beneficiaries: PAC, } \\
\text { Department of Environment }\end{array}$ \\
\hline $\begin{array}{l}\text { Capacity building, } \\
\text { academic research } \\
\text { and studies on forest } \\
\text { change using GIS } \\
\text { and Remote Sensing } \\
\text { within the University } \\
\text { of Guyana (UoG) }\end{array}$ & $\begin{array}{l}\text { Impacts: Scientific } \\
\text { research, papers and spatial } \\
\text { products produced by the } \\
\text { UoG that can be used to } \\
\text { inform policy, natural } \\
\text { resources planning, } \\
\text { management and usage, and } \\
\text { conservation efforts. } \\
\text { Beneficiaries: UoG }\end{array}$ \\
\hline $\begin{array}{l}\text { Managing and } \\
\text { protecting the } \\
\text { natural } \\
\text { environment, } \\
\text { specifically } \\
\text { regarding activities } \\
\text { being undertaken } \\
\text { within Guyana's } \\
\text { forests }\end{array}$ & $\begin{array}{l}\text { Impacts: Informing a } \\
\text { compliance monitoring } \\
\text { programme for the activities } \\
\text { undertaken within the } \\
\text { forested areas of Guyana. } \\
\text { Beneficiaries: EPA, } \\
\text { Department of } \\
\text { Environment, MNR }\end{array}$ \\
\hline $\begin{array}{l}\text { Informing planning } \\
\text { and decision making } \\
\text { for infrastructure } \\
\text { development and } \\
\text { climate resilience }\end{array}$ & $\begin{array}{l}\text { Impacts: National } \\
\text { infrastructural development } \\
\text { informed by data that helps } \\
\text { to plan for and reduce the } \\
\text { impact on forests. } \\
\text { Beneficiaries: Ministry of } \\
\text { Communities, Ministry of } \\
\text { Public Infrastructure, } \\
\text { Guyana Energy Agency }\end{array}$ \\
\hline $\begin{array}{l}\text { Impacts: Improved disaster } \\
\text { preparedness and response } \\
\text { Beneficiaries: } \\
\text { Hydrometeorological } \\
\text { Department, Ministry of } \\
\text { Agriculture }\end{array}$ \\
\hline
\end{tabular}




\begin{tabular}{|l|l|}
\hline Application & Impacts and beneficiaries \\
\hline Mangrove mapping & $\begin{array}{l}\text { Impacts: Baseline map will } \\
\text { allow for monitoring of } \\
\text { changes in mangroves along } \\
\text { Guyana's coast; to inform } \\
\text { policy regarding mangrove } \\
\text { protection and replanting. } \\
\text { Beneficiaries: Ministry of } \\
\text { Agriculture, National } \\
\text { Agricultural Research and } \\
\text { Extension Institute }\end{array}$ \\
\hline $\begin{array}{l}\text { Informing national } \\
\text { policy and reporting } \\
\text { on forest at the level } \\
\text { of Sustainable } \\
\text { Development Goals, } \\
\text { International } \\
\text { Commitments (Paris } \\
\text { Agreement), and } \\
\text { Bilateral } \\
\text { Agreements }\end{array}$ & $\begin{array}{l}\text { Impacts: A data agnostic } \\
\text { system built by Guyana } \\
\text { with strong local capacities } \\
\text { to operate, that serves } \\
\text { national and international } \\
\text { monitoring requirements, } \\
\text { and which inform decision } \\
\text { making and policy setting } \\
\text { for the natural resources } \\
\text { sector in Guyana. } \\
\text { Beneficiaries: Government } \\
\text { of Guyana }\end{array}$ \\
\hline
\end{tabular}

Table 5 - Summary of current MRVS applications

\section{POTENTIAL BROADER APPLICATIONS OF MRVS}

The main finding of the national review was the considerable interest across multiple Government agencies and non-government organisations in the use of MRVS data, for existing uses and a broader range of potential applications linked to their areas of work and broader than the current uses.

The review also noted the scope for these additional applications to be considered in the context of a range of key considerations that include (but were not limited to):

- The level of effort in terms of technical staff, time and costs involved to incorporate the additional functionality into the MRVS, where applicable;

- The extent to which this development would enhance the MRVS overall;

- The extent to which these applications will provide benefit for Guyana more broadly i.e. through improving land management across land tenures by providing increased access for Government agencies, NGOs and other stakeholders to current spatial data information and analysis.

In this context, the additional potential applications were compared and categorised into three distinct groupings that relate specifically to the level of effort required for applying or otherwise using the MRVS outputs for additional value-added purposes. These groupings comprise:

a. Options requiring a relatively low level of effort for implementation:

- Development of Land Use Plans: MRVS data could contribute to the refinement of the National Land Use Plan (NLUP) and preparation of land use plans. Low enhancement to the MRVS (data sharing). Benefit to Guyana: Medium to High.
- Monitoring of agricultural land use changes (LUC) in State lands: MRVS data can be used in the assessments of land under agricultural leased and permits, and to monitor trends in LUC and area availability. MRVS data is updated annually and this may be limiting for ongoing monitoring. Low enhancement to the MRVS (data sharing).

- Supporting management and monitoring of Protected Areas: MRVS data can support the monitoring of protected areas, identification of hotspots, and refinement of the strategy to add 2 million hectares of protected areas as per NDC commitments. Low enhancement to the MRVS (data sharing). Benefit to Guyana: High

- Monitoring forest biodiversity: MRVS data may contribute to monitoring biodiversity loss associated with forest loss and changes and impact on canopy cover. Low enhancement to the MRVS (data sharing). Benefit to Guyana: Medium to high

- Supporting EPA with compliance assessments: MRVS data can assist EPA to target auditing activities related to compliance on environmental management within concession areas (e.g. for mining or timber harvesting). As MRVS data is updated annually and this may be a limitation. Low enhancement to the MRVS (data sharing). Benefit to Guyana: Medium to high

b. Options requiring a medium level of effort for implementation:

- Mangroves mapping and monitoring: MRVS could be extended to include mangroves and provide information to assist in planning restoration and interventions. Medium to high scale MRVS enhancement with new methodologies required. Benefit to Guyana: Medium to high.

- Assistance in reporting obligations under the United Nations Convention to Combat Desertification (UNCCD): MRVS data can be shared to contribute to Guyana's reporting requirement commitments under this convention. The enhancement to the MRVS will be medium. Benefit to Guyana: High

- Deployment of GFC-MRVS personnel to assist other agencies: Through the MRVS development, GFC has built a relatively high level of personnel expertise in the development of systematic monitoring systems, and the analysis and application of satellite imagery. GFC would be assisting other agencies primarily through training and extension, and technical advisory support. GFC effort required could be at a low to medium level, and enhancements to the MRVS would be low to medium. Benefit to Guyana: High.

- Integrating Community MRV data: GFC has worked with communities to build capacities and test the efficacy and value of communitybased monitoring to the national MRVS. These data would provide at a minimum ground truthing or verification data to the national assessment. The potential enhancement to the 
MRVS is considered at a medium to high level. Benefit to Guyana: High.

c. Options requiring a relatively high level of effort for implementation:

- National Forest Inventory (NFI): GFC is set to undertake a second NFI. This would complement the second phase of MRVS implementation and provide updated quantification of forest biomass across all forest types, ground truthing information to quantify forest area, and forest biomass data to improve emission factors according to the stratification used. High level enhancement of the MRVS, and information across government. Benefit to Guyana: High.

- Contribution to forest monitoring systems to support FLEGT VPA with the EU: The MRVS would support the monitoring functions to help Guyana on its monitoring obligations under the FLEGT VPA ${ }^{6}$ signed in 2018. This will require a medium level of enhancement of the MRVS, with tailored reports to meet the requirements. Benefit to Guyana: Medium.

- Identification of forest ecosystem services and valuation of natural capital: Identified as a priority for Guyana, as forests are a dominant component of its natural capital. Substantial enhancement of the MRVS as new attributes for forest cover and non-forest areas would be required. Benefit to Guyana: High.

4.1 Guyana's Nationally Determined Contributions and the Sustainable Development Goals

Guyana's Nationally Determined Contributions outlined domestic conditional and unconditional contributions to the global effort to combat climate change. In its NDC, it is noted that "...Guyana is offering to defer the pursuit of our historic natural resource exploitation-based economy, and offer our huge carbon stocks to the world if, in return, our sustainable human development needs and the cost of deferring business as usual are met by financial support from the international community in a predictable, just and equitable manner." The NDC commits Guyana to the utilisation of a combination of forest conservation and sustainable forest management and utilisation.

The findings from the MRVS were used to inform the design of the commitments of the NDC, by providing information on the effects of the direct drivers of forest change. The MRVS was further used to inform the contribution of the additional 2 million hectares for conservation through Guyana's National Protected Area System (NPAS) and other effective area-based conservation measures. This led to the NDC commitments focusing on the forest and energy sectors, which account for the majority of current and historic emissions.

The MRVS has been given prominence within the NDC as a conditional contribution, whereby Guyana has committed to the completion and maintenance of building

6 Guyana's Revised Intended Nationally Determined Contribution, 2015:https://www4.unfccc.int/sites/ndcstaging/PublishedDocuments/Guy ana\%20First/Guyana\%27s\%20revised\%20NDC\%20-\%20Final.pdf the national MRVS, provided that adequate financial resources are available to do so. More importantly, the MRVS will play a major role as the tool by which the progress in implementation of the NDC activities, in terms of emissions reduction, will be measured and reported to the UNFCCC.

Guyana has committed to the implementation of the Sustainable Development Goals (SDGs) as part of the 2030 Agenda for Sustainable Development. Guyana is using a multi-stakeholder approach to implement programmes and projects to achieve the SDG targets and goals. The First Voluntary National Review was conducted in 2019, with the GFC being tasked with reporting on progress across multiple SDG indicators.

With the data already collected by the MRVS, the GFC was able to report on the progress of the indicators under SDG 15 - Protect, Restore and Promote Sustainable Use of Terrestrial Ecosystems, Sustainably Manage Forests, Combat Desertification, and Halt and Reverse Land Degradation and Halt Biodiversity Loss. Through the MRVS, Guyana was able to provide consistent information on the forest indicators for the review period.

The GFC will continue to use the MRVS data for future reporting on the progress of SDGs that relate to forest and climate change in Guyana.

\subsection{Potential applications in the Private Sector}

While the MRVS lends itself to applications in the public sector, specifically in relation to land use governance across predominantly public land in Guyana, the review also identified several opportunities for increased use of MRVS data by the private sector.

Most notably, the Forest Products Association (FPA) of Guyana, which represents over 200 forest industry members including small scale concession holders, contributed to the national review by observing its members have used the MRVS data on an ad hoc basis to look at activity within and around their concessions designed for timber harvesting activities, and to identify planned or unplanned activities and the impact on forest condition. Concessionaires have also used the imagery acquired for the MRV data to assist on occasion in planning the management of specific concessions; including access arrangements and managing proximity to other land uses.

The change in the MRV program to use of freely acquired Sentinel data will enable more ready access for this purpose, in contrast to the RapidEye imagery, which required licensing. The FPA has indicated that its members would like to make more use of this data than in the past; and is looking for the means and resources to access and analyse this data on a more regular basis.

\section{A BROADER VISION}

The recent national review highlighted the scope for the GFC and the MRVS to provide a broader range of applications that support land use policy and allocation and foster inter-agency collaboration. To do so, continued 
improvements in the System are required. The GFC and other program stakeholders have identified a set of key improvements that generally relate to making the System more efficient as well as enabling broader applications of the MRVS data.

One key improvement is the move to the use of freely available imagery. From the outset, the GFC has made incremental gains through the inclusion of new sources of satellite data and refinement of mapping and reporting processes. The GFC has tried and tested a range of satellite imagery data sources, both freely available and those paid for by the GFC. The data that has been paid for are governed by contract and licensing restrictions that prevent the GFC from sharing these images.

From 2016 to present, the GFC has been using freely available imagery (i.e. Sentinel and Landsat) to report on forest change. These images are not bound by licensing restrictions and can be shared with partners.

Furthermore, as the GFC continues to implement the MRVS, it will aim towards developing operational procedures for implementation of forest monitoring that can be sustained as a routine function of the GFC, with or without REDD+ financing. This will be done though the continued exploration of no-cost and low-cost alternatives to allow for the MRVS to be more dynamic in terms of implementation for other functions and in the absence of a full cost budget.

Another means by which the GFC is working to make the MRVS more accessible and user-friendly is through the development of a centralised information platform. Using the MNR as the focal point for this information platform, the data and results generated under the MRVS can be applied to wider land use management and policy for planning as well as addressing the key drivers of deforestation and forest degradation in the country. The GFC has commenced the exploration of options to establish linkages within the MNR, whereby the data and results obtained through annual assessments under the MRVS can be made available through an online portal to inform land use planning and management. This will effectively strengthen forest management by assisting forest owners and managers to proactively make better decisions for the management of Guyana's forests, and consequently strengthen the national REDD+ programme.

The GFC continues to move the MRVS towards more near real-time monitoring. This has been identified as one of the major improvements to the System that would enable wider applications of the MRVS data. The GFC is exploring the use of Sentinel imagery as an option for continuous resources monitoring. The Sentinel mission provides global coverage of the Earth's land surface every 10 days with one satellite and every five days with two satellites, making the data a valuable resource for monitoring forest change. Increased use of satellite data will allow for an increase in temporal resolution, thus having access to more data to confirm an observation.

With the responsibilities for reporting on the progress of implementation of the NDC commitments and the SDG indicators specific to forests, the scope of the MRVS has thus been widened. Additional capacities would have to be built to allow for mainstreaming of reporting in some of these areas. This would further necessitate a more real time and continuous monitoring system.
Along with the MRVS data and results, the GFC continues to prepare non-technical communication materials such as videos, booklets and other printed materials on the on the MRVS design, results and impact. These materials are developed using non-technical and user-friendly language and are used to promote stakeholder awareness and understanding of the MRVS. These materials are made available online as well as are distributed at relevant national, regional and international fora.

\section{ACKNOWLEDGEMENTS}

The Guyana Forestry Commission (GFC) would like to thank the Government of the Kingdom of Norway for supporting Guyana's work on the MRVS development from 2010 to present. The GFC also recognises its close partners in the development of the MRV System: Indufor Asia Pacific and Winrock International.

\section{REFERENCES}

Government of the Co-operative Republic of Guyana, 2019. Guyana First Voluntary National Review of the Sustainable Development Goals, July 2019.

Government of the Co-operative Republic of Guyana, 2015. Guyana's Revised Intended Nationally Determined Contribution.

Government of Guyana and United Nations Environment Programme (UNEP), 2017. Framework of the Guyana Green State Development Strategy and Financing Mechanisms, March 2017.

Government of Guyana and the Food \& Agriculture Organization (FAO), 2017. Mainstreaming Sustainable Land Development and Management in the Co-operative Republic of Guyana, August 2017.

Government of Guyana, 2014. The Reference Level for Guyana's REDD+ Program, December 2014.

Guyana Forestry Commission, 2018. Guyana REDD+ Monitoring Reporting \& Verification System (MRVS) Year 7 Interim Measures Report, November 2018.

Guyana Forestry Commission, 2014. Terms of Reference for continuing to Develop Capacities for a National Forest Monitoring and Measurement, Reporting and Verification System to Support REDD+ Participation of Guyana, Roadmap Phase 1 Achievements, Evolving Requirements and Roadmap for Phase 2 Activities, September 19, 2014.

Guyana Forestry Commission, 2009. Terms of Reference for Developing Capacities for a national Monitoring, Reporting and Verification System to support REDD+ participation of Guyana Background, Capacity Assessment and Roadmap, November 13, 2009.

Government of Guyana, 2012. Joint Concept Note, March 31, 2012. 